\title{
TELAAH PENERAPAN SEGMENTASI PASAR \\ PADA UKM SARUNG TANGAN
}

\author{
ROSITA \\ Universitas Terbuka
}

\section{Profil Perusahaan}
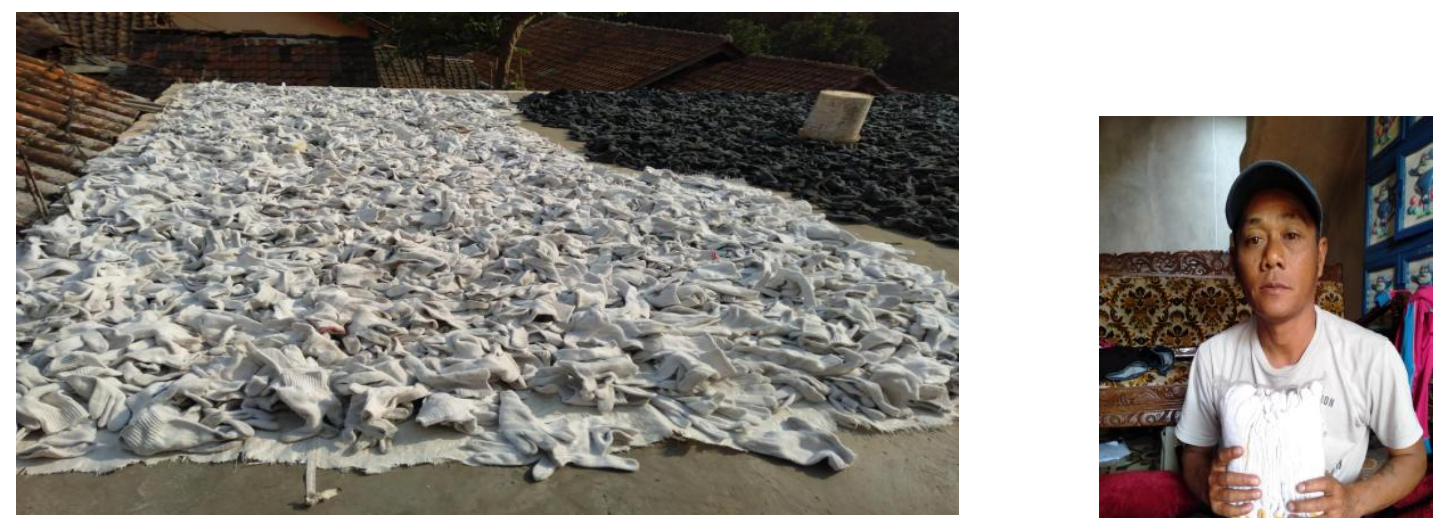

\section{INDUSTRI SARUNG TANGAN}

Perusahaan yang bergerak di segmentasi pasar usaha kecil. Saya Aas Suryana 45 Tahun, saya mulai mendirikan usaha ini pada tahun 1 Februari 2011 dalam bidang sarung tangan untuk kebutuhan lingkungan, pribadi dan lain lain. Untuk memberikan pelayanan terbaik kepada semua konsumen, kami memberikan penawaran harga terbaik dan kompetitif. Untuk menarik minat konsumen pada usaha kecil masih sangatlah sulit. Salah satu cara yang dapat di gunakan untuk mengembangkan usaha kecil tentunya dengan fokus pada strategi pemasaran.

Dengan terbatasnya anggaran marketing yang dimiliki usaha kecil, bukan berarti menjadikan usaha kecil kalah dengan usaha skala besar. Untuk itu perusahaan kami harus lebih kreatif dengan anggaran biaya yang minim untuk menghasilkan strategi pemasaran yang tepat.

Bersama dengan 4 karyawan saya kita semua berusaha meningkatkan budaya bisnis kami, memastikan lingkungan kerja yang aman bagi karyawan, perbaikan mutu yang berkelanjutan, memastikan pengiriman barang tepat waktu, dan memenuhi lebih dari yang di harapkan pelanggan.

\section{Jenis produk yang di jual dan harganya}




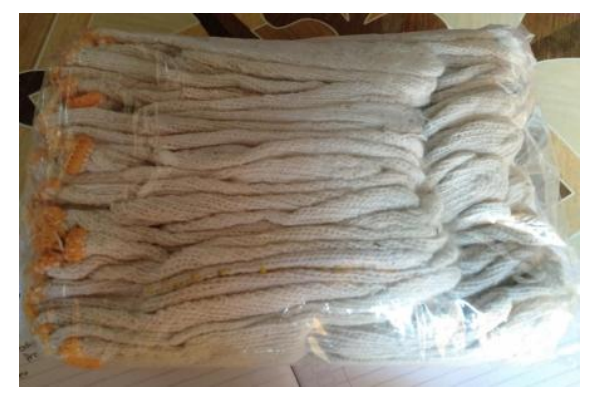

Jenis poduk yang di jual adalah sebuah sarung tangan yang di buat dari benang wol yang berfungsi untuk melindungi tangan dari benda atau permukaan yang tajam bergelombang dan kotor. Harga produk perlusin Rp. 20.000 sedangkan perhari nya perusahaan kami memproduksi 50 lusin perhari, jadi total pendapatan kas kami Rp. 1.000.000 perhari namun kita outar kembali laba kami ke modal awal perusahaan agar pendapatan dan peningkatan produksi meningkat.

\section{Bentuk promosi apa yang di lakukan}

Promosi dan iklan merupakan konsep marketing yang harus di pertimbangkan pada berbagai bisnis dan produk, termasuk pada usaha kecil. Promosi dan iklan yang baik akan menghasilkan pengakuan brand yang efektif hingga mampu meningkatkan penjualan. Sekarang kita mulai mencoba bisnis lewat website juga karena $45 \%$ konsumen datang dari informasi dari internet sehingga peningkatan jumlah pelanggan tertarik dengan produk kami. Bekerja sama dengan pengusaha atau rekan pemasangan iklan, mencoba megirimkan penawaran produk kepada pelanggan serta memberikan potongan harga.

\section{Siapa saja konsumen yang membeli produknya}

Bekerja sama dengan pengusaha yang salah satunya membutuhkan produk usaha kami. Contoh seperti :

* Budidaya Peternak ayam

* Arsitektur lapangan

* Warga sekitar

Berhubung sarung tangan adalah salah satu safety dalam suatu pekerjaan yang melindungi dari keselamatan kerja jadi setiap golongan konsumen ada. 
Analisis :

1. Merujuk pada faktor-faktor segmentasi, menurut anda karakteristik konsumen usaha tersebut termasuk faktor segmentasi yang mana? Jelaskan alasan anda!

2. Sebutkan strategi apa saja yang perlu dilakukan agar usaha tersebut berada pada posisi yang terbaik di pasar?

Jawab :

1. Usaha yang saya ambil dalam tugas ini ialah masuk kedalam faktor demografis geografis, karena usaha dalam lokasi yang strategis, dan faktor yang di gunakan dalam suatu perusahaan untuk mensegmentasikan pasar organisasional atau pasar bisnis ialah ukuran perusahaan, usia perusahaan, bahasa yang di gunakan pola pertumubuhan untuk industri dan perusahaan, penggunaan produk untuk produksi, di jual lagi, jenis institusi seperti manufaktur, pedagang besar, pengecer, pemerintah, non laba dan jenis industri.

2. Strategi yang perlu di lakukan dalam dalam usaha ini ialah selalu memberikan pelayanan yang terbaik untuk konsumen, target atau segmen pasar harus dapat di akses oleh bisnis, masing masing kelompok segmentasi harus cukup besar sehingga dapat di gunakan sebagai dasar pelanggan yang solid, adanya konsistensi terhadap semua area marketingnya dapat membantu mengurangi biaya marketing dan meningkatkan efektivitas penciptaan merek. Strategi merupakan dasar untuk kelanjutan kegiatan marketing yang telah di rencanakan misalnya siapa target pasar,bagaimana usaha kecil membidi pelanggan, dan bagaimana cara menjaga konsumen yang ada sebagai pelanggan tetap.

\section{Referensi}

Fadillah, A., Sujana, S. and Sukartaatmadja, I., 2019. Kajian Minat Studi Lanjut Siswa-Siswi SMA dan SMK Kota Bogor Ke Perguruan Tinggi. JAS-PT (Jurnal Analisis Sistem Pendidikan Tinggi Indonesia), 3(1), pp.53-62.

Mulyana, M., 2019. MENGANALISIS PERILAKU KONSUMEN.

Mulyana, M., 2019. STRATEGI PROMOSI DAN KOMUNIKASI.

Mulyana, M., Hidayat, L. and Puspitasari, R., 2019. Mengukur Pengetahuan Investasi Para Mahasiswa Untuk Pengembangan Galeri Investasi Perguruan Tinggi. JAS-PT (Jurnal Analisis Sistem Pendidikan Tinggi Indonesia), 3(1), pp.31-52.

Sulistiono, S., Nurendah, Y. and Mulyana, M., 2019. Mengukur Minat Studi Siswa SMA dan SMK di Kota Bogor Pada Program Studi Kewirausahaan. JAS-PT (Jurnal Analisis Sistem Pendidikan Tinggi Indonesia), 3(1), pp.1-12.

Sukartaatmadja, I., Thoyibah, H., Mulyana, M. and Yusdira, A., 2019. PELATIHAN DIGITAL LIBRARY BAGI PENGELOLA PERPUSTAKAAN PERGURUAN TINGGI SE-BOGOR. 
Setiawan, B., Puspitasari, R. and Manurung, T.M.S., 2016. The existence of Islamic banking in Indonesia from non-muslims perceptions. ASEAN Marketing Journal, pp.81-96.

Hidayat, L., Amwilla, A.Y. and Aprilia, A., 2015. Analisis Perputaran Modal Kerja, Perputaran Aktiva Terhadap Tingkat Pengembalian Modal. Jurnal Ilmiah Manajemen Kesatuan, 3(1).

Purba, J.H.V. and Munawar, A., 2008. Kajian Dampak Pelatihan terhadap Kinerja Karyawan. Jurnal Ilmiah Ranggagading (JIR), 8(2), pp.95-102.

Purba, J.H.V. and Hartoyo, S., 2018. Dampak Kenaikan Harga Minyak Bumi terhadap Permintaan CPO untuk Biodiesel dan Beberapa Aspek Pada Industri Kelapa Sawit Indonesia. JIMFE (Jurnal Ilmiah Manajemen Fakultas Ekonomi), 2(1), pp.37-49. 